\title{
Dimethyl Fumarate Treatment in Patients With Primary Progressive Multiple Sclerosis
}

\author{
A Randomized, Controlled Trial
}

\author{
Helene Højsgaard Chow, PhD, Jacob Talbot, MD, Henrik Lundell, PhD, Camilla Gøbel Madsen, MD, \\ Lisbet Marstrand, PhD, Theis Lange, PhD, Mie Reith Mahler, MD, Sophie Buhelt, PhD, Rikke Holm Hansen, MSc, \\ Morten Blinkenberg, PhD, Jeppe Romme Christensen, PhD, Per Soelberg Sørensen, DMSc, \\ Marina Rode von Essen, PhD, Hartwig Roman Siebner, DMSc, and Finn Sellebjerg, DMSc
}

Neurol Neuroimmunol Neuroinflamm 2021;8:e1037. doi:10.1212/NXI.0000000000001037

\section{Abstract}

\section{Background and Objective}

To study whether dimethyl fumarate is superior to placebo in decreasing CSF concentrations of neurofilament light chain (NFL) in patients with primary progressive MS (PPMS).

\section{Methods}

In the double-blind, placebo-controlled phase 2 study dimethyl FUMArate treatment in Progressive Multiple Sclerosis (FUMAPMS), patients with PPMS were randomly assigned to treatment with $240 \mathrm{mg}$ dimethyl fumarate or placebo in a 1:1 ratio for 48 weeks. The primary endpoint was change in concentration of NFL in the CSF. Secondary endpoints included other CSF biomarkers and clinical and MRI measures. Efficacy was evaluated for the full data set by multiple imputations to account for missing data. Safety was assessed for the full data set.

\section{Results}

Fifty-four patients (mean age 54.9 years [SD 6.1], median Expanded Disability Status Scale 4.0 [nterquartile range 4.0-6.0], disease duration 14.1 [SD 9.4], and 21 [39\%] female) were randomized to either placebo $(n=27)$ or dimethyl fumarate $(n=27)$ therapy. At screening CSF concentrations, adjusted for age and sex, of NFL, myelin basic protein (MBP), soluble CD27, chitinase 3-like 1, and $\mathrm{B}$-cell maturation antigen were higher than in a group of symptomatic controls. Twenty-six patients (96\%) in the dimethyl fumarate group and 24 patients (89\%) in the placebo group completed the randomized phase. Mean change in CSF concentrations of NFL did not differ between groups (mean difference $99 \mathrm{ng} / \mathrm{L} ; 95 \% \mathrm{CI}-292$ to $491 \mathrm{ng} / \mathrm{L}$ ). MBP in CSF decreased in the treatment group ( $-182 \mathrm{ng} / \mathrm{L}, 95 \% \mathrm{CI}-323$ to $-41 \mathrm{ng} / \mathrm{L}$ compared with placebo). The difference observed in the multiple imputation data set was not significant in a per protocol analysis. This was nominally significant in the multiple imputation data set but not in the per protocol analysis This was not found in the per protocol analysis Other secondary and tertiary outcomes were not affected. Various infections, lymphopenia, flushing, and gastrointestinal side effects were more frequent in the dimethyl fumarate group. Serious adverse events were similar between groups.

\section{Discussion}

Dimethyl fumarate treatment for 48 weeks had no effect on any of the investigated efficacy measures in patients with PPMS. We did not observe adverse events not anticipated for dimethyl fumarate treatment.

\author{
Correspondence \\ Dr. Sellebjerg \\ sellebjerg@dadlnet.dk
}

MORE ONLINE

(II) Class of Evidence

Criteria for rating

therapeutic and diagnostic

studies

NPub.org/coe 


\section{Glossary}

9HPT $=$ Nine-Hole Peg Test; BCMA = B-cell maturation antigen; CHI3L1 = chitinase 3-like 1; CTCAE = Common Terminology Criteria for Adverse Events; EDSS = Expanded Disability Status Scale; MBP = myelin basic protein; NFL = neurofilament light chain; PPMS = primary progressive MS; RRMS = relapsing-remitting MS; $\mathbf{s C D 1 4}$ = soluble CD14; sCD27 = soluble CD27; SDMT = Symbol Digit Modalities Test; SIMOA = single-molecule array; T25FW = Timed 25-Foot Walk.

Trial Registration Information

Clinicaltrials.gov identifier NCT02959658.

\section{Classification of Evidence}

This study provides Class I evidence that for patients with PPMS, dimethyl fumarate treatment has no effect on CSF NFL levels compared with placebo treatment.

Patients with primary progressive MS (PPMS) comprise approximately $10 \%-15 \%$ of the total MS patient population. Several treatment trials conducted in patients with PPMS have been unsuccessful, although the B-cell-depleting antibody ocrelizumab recently proved efficacious. ${ }^{1,2}$

Dimethyl fumarate is approved in Europe for patients with relapsing-remitting MS (RRMS) and in the United States as treatment for relapsing forms of MS, but the effect of dimethyl fumarate in PPMS is uncertain. ${ }^{3,4}$ One pilot study showed that fumaric acid esters were well tolerated in a cohort of patients with progressive MS and observed no disease progression in $75 \%$ of treated patients. ${ }^{5}$ Studies suggest that dimethyl fumarate possesses immunomodulatory and neuroprotective properties by promotion of the nuclear factor erythroid-derived 2 transcriptional pathway and by inhibition of the nuclear factorkappa B signaling pathway. ${ }^{6}$ In addition, dimethyl fumarate and its metabolite monomethyl fumarate induce depletion of specific T-cell and B-cell subsets and cross the blood-brain barrier. ${ }^{7,8}$ Therefore, dimethyl fumarate may be beneficial in the treatment of patients with PPMS.

Phase 2 trials with brain atrophy as primary outcome have recently been conducted in patients with progressive MS but require several 100 patients and 2 years of follow-up. ${ }^{9,10}$ Changes in the CSF concentration of neurofilament light chain (NFL) have been explored as outcome measure in phase 2 studies in progressive MS. ${ }^{11,12}$ More recently, the serum concentration of NFL has been proposed as a treatment-responsive biomarker in progressive MS. ${ }^{13}$ Although NFL can be measured in serum, the concentrations are much higher in CSF, and CSF studies allow for the additional analysis of other biomarkers of intrathecal inflammation and tissue damage. ${ }^{13-16} \mathrm{NFL}$ is stable in longitudinal analyses of patients with MS, as shown in this article and others. ${ }^{17}$ These properties make NFL a promising biomarker for trials in progressive MS with smaller sample sizes. Here, we report the results from the first randomized, double-blind, placebo-controlled study of dimethyl fumarate in patients with
PPMS in which we used changes in the CSF concentration of NFL as a primary outcome measure.

\section{Methods}

\section{Study Design and Patients}

We conducted a randomized, double-blind, placebo-controlled trial to test the superiority of dimethyl fumarate vs placebo in patients with PPMS. This study was a single-center study executed at the Danish Multiple Sclerosis Center, Copenhagen University Hospital-Rigshospitalet in Denmark. The randomized phase was followed by an open-label extension phase for 48 weeks. Here, we report the results from the double-blind part. Eligible patients aged 18-65 years, had an Expanded Disability Status Scale (EDSS) score between 0 and 6.5, were diagnosed with PPMS, and had a CSF concentration of NFL above $380 \mathrm{ng} / \mathrm{L}$. Key exclusion criteria were immunomodulatory treatment within 6 months or treatment with steroids within 3 months, significant psychiatric disorders, and/or active or chronic infection with HIV or hepatitis A or B. The full lists of inclusion and exclusion criteria and primary, secondary, and tertiary outcome measures are provided in eSupplemental Material 1 (links.lww.com/NXI/A507).

We compared baseline concentrations of CSF biomarkers in the patients with PPMS with samples from symptomatic controls who were defined as having neurologic symptoms but had no objective or paraclinical findings to define a specific neurologic disease. ${ }^{18}$

\section{Standard Protocol Approvals, Registrations, and Patient Consents}

This study was undertaken in accordance with the International Conference on Harmonization of Good Clinical Practice, the Declaration of Helsinki, and the local ethics committee (H-16032162). Data monitoring was provided by the Good Clinical Practice Unit at Copenhagen University Hospital. All patients provided written informed consent. The 
study protocol is available at dmsc.dk. A full description of changes made to methods and outcome measures after trial commencement, recruitment, authorities and oversight is given in eSupplemental Material 2 (links.lww.com/NXI/A508).

This study is registered at ClinicalTrials.gov, number: NCT02959658. This study followed the Consolidated Standards of Reporting Trials reporting guidelines for randomized clinical trials.

\section{Randomization and Masking}

Fifty-four patients were randomly assigned 1:1 to receive twicedaily oral dimethyl fumarate $240 \mathrm{mg}$ or placebo (Biogen, Cambridge, MA). From days 1-21, the study drug dose was titrated from 120 to $480 \mathrm{mg}$ as a daily maintenance dose. Study drug and placebo capsules were identical and with identical packaging, labeling, expiration date, taste, and odor. The randomization and masking were performed by the Regional Capital Pharmacy in Copenhagen. Blinding of patients and physicians was maintained throughout this study, but common side effects of the study drug were evaluated by the investigators.

\section{Procedures}

Lumbar puncture was performed at screening and week 48. CSF concentrations of NFL were analyzed by a commercially available ELISA (UMAN Diagnostics, Umeå, Sweden). All laboratory personnel were blinded to any clinical data or treatment group assignment. A full description of assay procedures is available in eSupplemental Material 3 (links.lww.com/NXI/ A509). MRI data were analyzed at the independent MRI reader center at Copenhagen University Hospital, Hvidovre, by staff unaware of treatment group assignment. All patients underwent MRI of the brain, including spinal C2 level, on the same 3T Verio MRI scanner (Siemens Healthcare, Erlangen, Germany). A full description of the MRI protocol is given in eSupplemental Material 4 (links.lww.com/NXI/A510). Assessment of walking range, functional systems, and EDSS was performed every 24 weeks by trained and certified investigators. Timed 25-Foot Walk (T25FW), Nine-Hole Peg Test (9HPT), and Symbol Digit Modalities Test (SDMT) were performed by trained study nurses or physicians.

\section{Outcome Measures}

The primary endpoint was change in CSF concentration of NFL from screening to week 48. Secondary endpoints were change in CSF concentrations of myelin basic protein (MBP), soluble B-cell maturation antigen (BCMA), chitinase 3-like 1 (CHI3L1), soluble CD27 (sCD27), soluble CD14 (sCD14), immunoglobulin $\mathrm{G}$ index, and albumin quotient; change in fractional anisotropy of normal-appearing white matter, magnetization transfer ratio of lesions, mean thalamic volume, difference in number of new and enlarged $\mathrm{T} 2$ lesions and percentage brain volume change; and change in EDSS, T25FW, 9HPT, and SDMT.

Adverse events were reported using Common Terminology Criteria for Adverse Events (CTCAE). Safety assessments included physical examination by the trial investigators every 24 weeks, along with vital parameters assessment and safety blood tests every 12 weeks. The same experienced neuroradiologist clinically interpreted all brain MRIs from screening and week 48 .

\section{Statistical Analysis}

Based on the results of previous studies of change in NFL in progressive MS, we estimated that there would be no change over 48 weeks in the placebo group (estimated SD 30\%) and that treatment would result in a $30 \%$ decrease in NFL in patients with baseline levels of NFL above $380 \mathrm{ng} / \mathrm{L}^{11,12,19}$ With a $1: 1$ randomization, inclusion of at least 42 patients gave the study $90 \%$ power to detect a $30 \%$ reduction in the CSF concentration of NFL with a significance level of 5\%. Analyses of primary and secondary endpoints (except new and enlarging lesions) were performed using one-way analysis of covariance with screening value as covariate and treatment group as the classification variable. Changes from screening to week 48 were derived from the model. For the analysis of new and enlarging lesions, we used a negative binomial regression model with the number of lesions at screening as covariate and treatment group as the classification variable. Fifty individuals completed the study per protocol, and the missing values for the remaining 4 patients were handled using multiple imputation $(\mathrm{m}=25,10$ iterations, linear regression method). All analyses were conducted on the imputed data set. Sensitivity analyses were conducted on the patients treated per protocol with at least $80 \%$ adherence to treatment. Secondary endpoints were tested at a nominal without adjustment for multiple testing. We used SPSS v25 for all statistical analyses.

\section{Role of the Funding Source}

The funders did not contribute to study design or implementation, data analyses, data interpretation, or writing. Biogen provided trial medicine at no cost. The corresponding author had full access to the data and had final responsibility for the decision to submit for publication.

\section{Data Availability}

Data are available in anonymized form and can be shared by request from any qualified investigator. Sharing requires approval of a data transfer agreement by the Danish Data Protection Agency.

\section{Results}

From December 6, 2016, to January 16, 2019, 54 patients (mean age 54.9 years [SD 6.1], median EDSS 4.0 [interquartile range (IQR) 4.0-6.0], disease duration 14.1 years [SD 9.4], and 21 [39\%] female) were randomized $1: 1$ to dimethyl fumarate or placebo treatment (Figure 1). Baseline demographics and disease characteristics were comparable between groups (Table 1 ). Fifty patients completed the study (24 assigned to placebo [48\%] and 26 assigned to dimethyl 


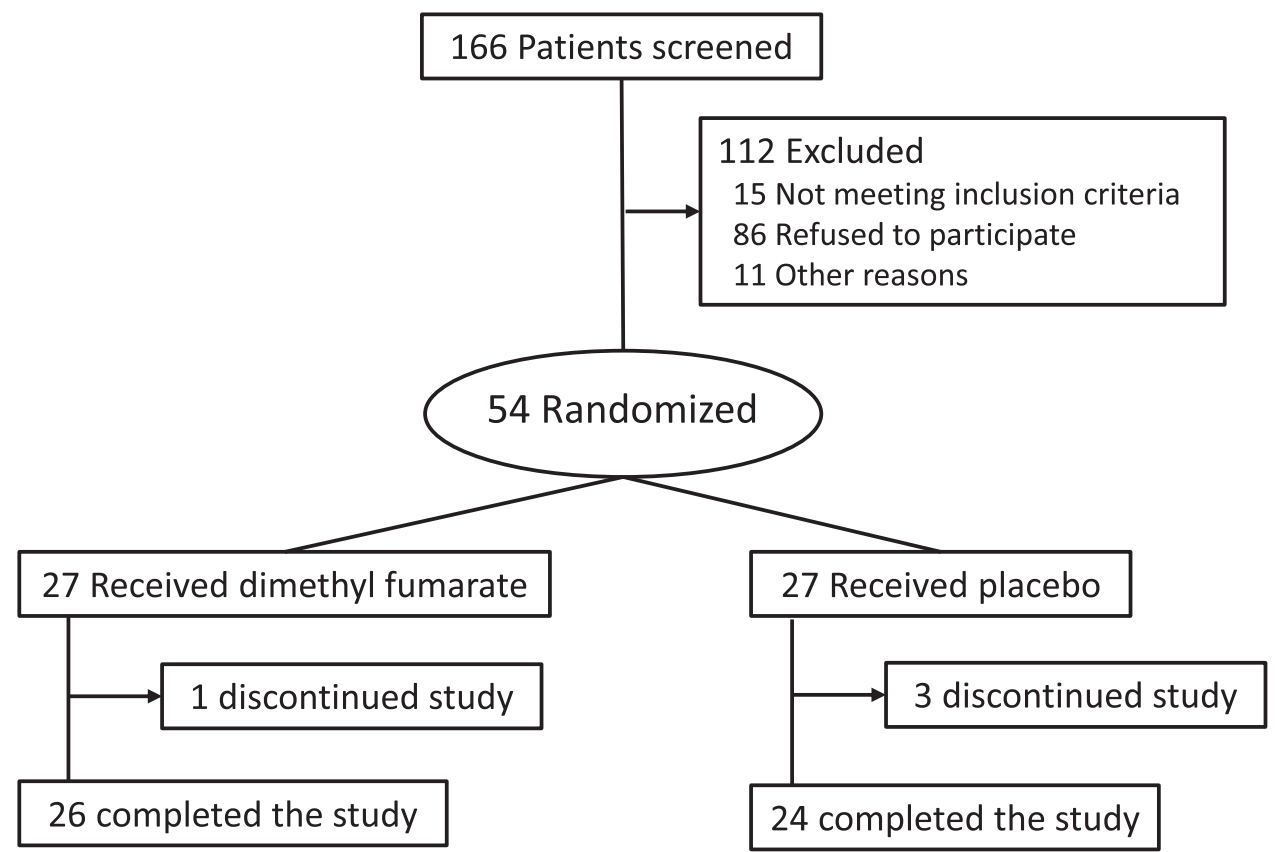

fumarate $[52 \%])$. All finishing patients $(\mathrm{n}=50)$ had at least $80 \%$ drug adherence. Compared with the placebo group, mean change in CSF NFL from screening to week 48 was insignificantly higher in the dimethyl fumarate group (99.3 ng/L, 95\% CI -291.8 to $490.4 \mathrm{ng} / \mathrm{L}, p=0.61$ ) (Table 2). In addition, no differences were found between the dimethyl fumarate group and the placebo group for any secondary

Table 1 Demographic and Baseline Disease Characteristics of Randomized Patients

\begin{tabular}{|c|c|c|}
\hline Characteristic & $\begin{array}{l}\text { Placebo } \\
(n=27)\end{array}$ & $\begin{array}{l}\text { Dimethyl fumarate } \\
(n=27)\end{array}$ \\
\hline Age, y; mean (SD) & $54.0(6.6)$ & $55.7(5.5)$ \\
\hline Female, n (\%) & $11(41 \%)$ & $10(37 \%)$ \\
\hline Disease duration, y; mean (SD) & $13.8(9.7)$ & $14.3(9.4)$ \\
\hline \multicolumn{3}{|l|}{ Cell count } \\
\hline >4 cells/ $\mu \mathrm{L}, \mathrm{n}(\%)$ & $4(14.8 \%)$ & $8(29.6 \%)$ \\
\hline \multicolumn{3}{|l|}{ Oligoclonal bands } \\
\hline Yes, n (\%) & $23(85.2 \%)$ & $25(92.6 \%)$ \\
\hline \multicolumn{3}{|l|}{ Gd-enhancing lesions ${ }^{a}$} \\
\hline $1, \mathrm{n}(\%)$ & $2(7.7 \%)$ & $3(11.1 \%)$ \\
\hline $0, \mathrm{n}(\%)$ & $22(84.6 \%)$ & $24(88.9 \%)$ \\
\hline NA, n (\%) & $2(7.7 \%)$ & $0(0.0 \%)$ \\
\hline
\end{tabular}

Abbreviation: $\mathrm{Gd}=$ Gadolinium .

${ }^{a}$ Two patients in the placebo group did not receive gadolinium contrast because of contraindications. outcome measures, except MBP which decreased in the dimethyl fumarate group ( $-182 \mathrm{ng} / \mathrm{L}, 95 \% \mathrm{CI}-323$ to $-41 \mathrm{ng} /$ $\mathrm{L}, p=0.01$ ). However, this difference was not significant in the sensitivity analyses (data not shown). The results on remaining secondary and all tertiary endpoints are given in eSupplemental Material 5 (links.lww.com/NXI/A511). There were no changes in any of these endpoints. To assess whether the lack of efficacy of treatment with dimethyl fumarate was due to lack of intrathecal inflammation in the patients, we compared levels of the biomarkers from this study with those of a symptomatic control cohort (Figure 2). At screening, CSF concentrations, adjusted for age and sex, of NFL, MBP, sCD27, CHI3L1, and BCMA were higher than in the group of symptomatic controls, whereas there was no increase in sCD14.

All eligible patients received at least 1 dose of trial medication and were, therefore, included in the safety evaluation (Table 3). Adverse events occurred in $89 \%$ and $59 \%$ of patients in the dimethyl fumarate and placebo groups, respectively. Common side effects of dimethyl fumarate occurred in $85 \%$ in the treatment group: 16 (59\%) experienced flushing; 15 (56\%) had gastrointestinal side effects; and 14 (52\%) had lymphopenia (grade 1 [4\%], 2 [30\%], or 3 [19\%]) at any point during the first phase of the study. No patients were terminated from the randomized phase of the trial because of lymphopenia. Aside from these side effects, the most frequent adverse event term of any grade was infections, which occurred in 11 patients $(41 \%)$ in the placebo group and 19 patients $(70 \%)$ in the treatment group. Especially flu-like symptoms were more prevalent in the treatment group (18.5\% vs $7.4 \%)$. The frequency of serious adverse 
Table 2 Primary and Selected Secondary Efficacy Endpoints

\begin{tabular}{|c|c|c|c|c|c|}
\hline \multirow[b]{2}{*}{ Efficacy measure } & \multicolumn{2}{|l|}{ Endpoint values } & \multirow{2}{*}{$\begin{array}{l}\text { Treatment effect, dimethyl } \\
\text { fumarate vs placebo }(n=54)^{a} \\
\text { Estimate }^{b}\end{array}$} & \multirow[b]{2}{*}{$95 \% \mathrm{Cl}$} & \multirow[b]{2}{*}{$p$-value ${ }^{c}$} \\
\hline & Placebo $(n=24)$ & Dimethyl fumarate $(n=26)$ & & & \\
\hline CSF NFL at baseline (ng/L) & $571(483-808)$ & $628(502-934)$ & & & 0.38 \\
\hline NFL change in CSF (ng/L) & $-73(190)$ & $35(1,002)$ & 99 & -292 to 490 & 0.61 \\
\hline \multicolumn{6}{|l|}{ Secondary } \\
\hline MBP at baseline (ng/L) & $469(340-580)$ & $425(356-723)$ & & & 0.77 \\
\hline MBP change (ng/L) & $18(200)$ & $-206(461)$ & -182 & -323 to 41 & 0.01 \\
\hline sCD27 at baseline (ng/L) & $1753(650-2586)$ & $1774(1,016-3,143)$ & & & 0.53 \\
\hline sCD27 change (ng/L) & $-188(321)$ & $-307(481)$ & -107 & 274 to 60 & 0.20 \\
\hline sBCMA at baseline (ng/L) & $938(601-1,346)$ & $1,026(692-1,332)$ & & & 0.60 \\
\hline sBCMA change (ng/L) & $-57(146)$ & $-96(204)$ & -30 & -103 to 42 & 0.41 \\
\hline sCD14 at baseline $(\mathrm{ng} / \mathrm{mL})$ & $103(88-113)$ & $106(94-132)$ & & & 0.25 \\
\hline sCD14 change (ng/mL) & $5(17)$ & $7(24)$ & 3 & -8 to 15 & 0.54 \\
\hline CHI3L1 at baseline $(\mathrm{ng} / \mathrm{mL})$ & $170(144-214)$ & $215(177-323)$ & & & 0.03 \\
\hline CHI3L1 change (ng/mL) & $-7(27)$ & $-17(47)$ & 1 & -18 to 20 & 0.91 \\
\hline No. of $\mathrm{T} 2$ lesions at baseline & $29(18-38)$ & $32(18-49)$ & & & 0.55 \\
\hline $\begin{array}{l}\text { New or enlarging } \mathrm{T} 2 \text { lesions } \\
\text { at week } 48^{\mathrm{d}}\end{array}$ & $3(4)$ & $3(3)$ & 0 & -1 to 0 & 0.49 \\
\hline NBV at baseline $(\mathrm{mL})$ & $1,454(1,364-1,487)$ & $1,453(1,412-1,498)$ & & & 0.56 \\
\hline PBVC at week 48 & $-0.2(0.8)$ & $-0.5(0.8)$ & -0.2 & -0.8 to 0.2 & 0.24 \\
\hline EDSS at baseline & $4.0(3.5-6.0)$ & $4.3(4.0-6.0)$ & & & 0.47 \\
\hline EDSS change & $0.0(1.0)$ & $0.2(0.7)$ & 0.29 & -0.1 to 0.7 & 0.16 \\
\hline $\begin{array}{l}\text { Abbreviations: BCMA = B-cell ma } \\
\text { neurofilament light chain; NVB = } \\
\text { Primary and selected secondary } \\
\text { eSupplementary Material } 5 \text { (links. } \\
\text { with SD. } \\
\text { a Missing values were imputed w } \\
\text { b Analyses were conducted by us } \\
{ }^{\circ} p \text {-Value was calculated from the } \\
\text { d Analysis was based on negative }\end{array}$ & $\begin{array}{l}\text { ation antigen; CHI3L } \\
\text { rmalized brain volum } \\
\text { dpoints. All changes } \\
\text { N.Com/NXI/A511). All } \\
\text { multiple imputations } \\
\text { f one-way ANCOVA n } \\
\text { ilcoxon signed rank t } \\
\text { homial regression ad }\end{array}$ & $\begin{array}{l}\text { Chitinase-3-like-1; EDSS = Expa } \\
\text { PBVC = percentage brain volum } \\
\text { ere calculated from screening t } \\
\text { seline values are presented as m } \\
\text { ee statistics). } \\
\text { i screening value as covariate a } \\
\text { t for baseline comparisons. } \\
\text { ted for number of T2-lesions at }\end{array}$ & $\begin{array}{l}\text { ded Disability Status Scale; MBP = } \\
\text { change; SCD14 = soluble CD14; } \\
\text { week } 48 \text {. Remaining secondary } \\
\text { dian with IQR. All differences in cha } \\
\text { d by use of multiple imputation fo } \\
\text { creening. }\end{array}$ & $\begin{array}{l}\text { nyelin basic pr } \\
\text { D27 = soluble } \\
\text { dpoint results } \\
\text { ges are presen } \\
\text { missing data. }\end{array}$ & $\begin{array}{l}\text { ein; } N F L= \\
27 . \\
\text { e given in } \\
\text { d as mean }\end{array}$ \\
\hline
\end{tabular}

events was similar between the 2 groups. Serious adverse events were testicular seminoma (4\%), gallbladder pain (4\%), and urosepsis (4\%) in the dimethyl fumarate group, and rotavirus gastroenteritis (4\%), vertigo (4\%), and urinary tract infection (4\%) in the placebo group. There were no cases of progressive multifocal encephalopathy nor any other opportunistic infections. No patients had elevated liver enzymes above the limits of grade 1 according to the CTCAE. The results for adverse events affecting less than $5 \%$ of the patients are given in eSupplemental Material 6 (links.lww.com/NXI/A512).

\section{Discussion}

This randomized controlled phase 2 study did not find a difference in the primary outcome of the study, change in CSF concentration of NFL, between patients treated with dimethyl fumarate or placebo. Neither did we find any difference in change in any CSF biomarkers of inflammation between patients treated with dimethyl fumarate or placebo, despite the patients having increased levels of most biomarkers of inflammation compared with symptomatic controls. All other secondary endpoints did not reveal any differences between the treatment and the placebo arm, except for a lowering of the CSF concentration of MBP in the dimethyl fumarate group which was not found in the per protocol analysis. Previous studies have shown that MBP levels in the CSF of patients with MS decrease on treatment with cyclophosphamide, natalizumab, or methylprednisolone, supporting the use of MBP as a treatment-responsive biomarker of demyelination in patients with MS. ${ }^{12,20,21}$ 
A

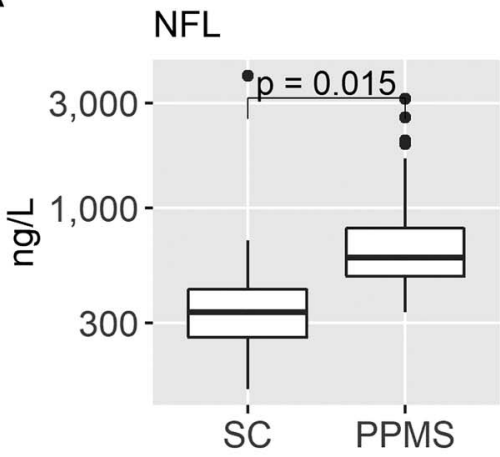

D

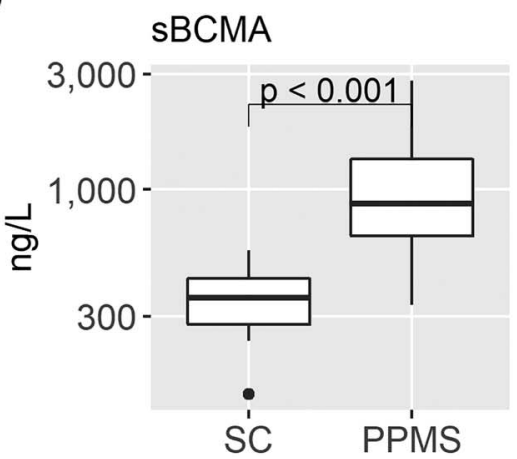

B

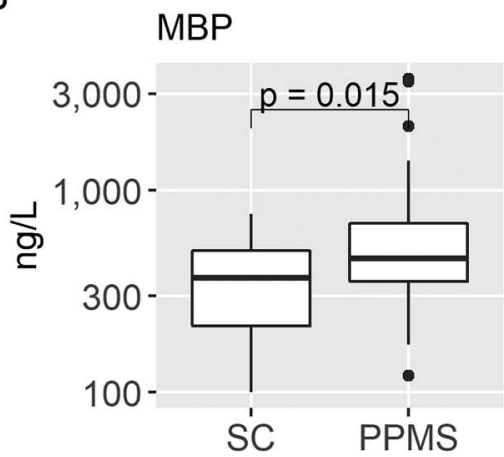

E

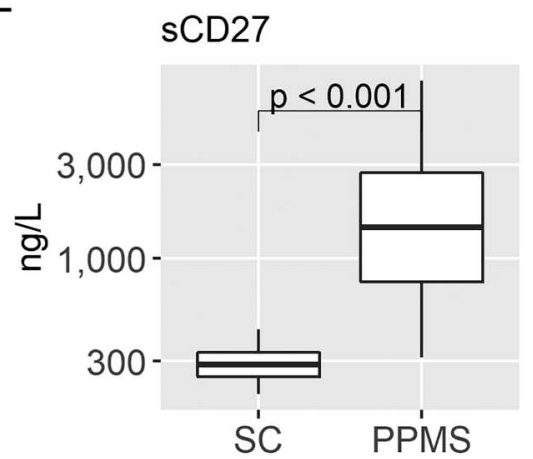

C

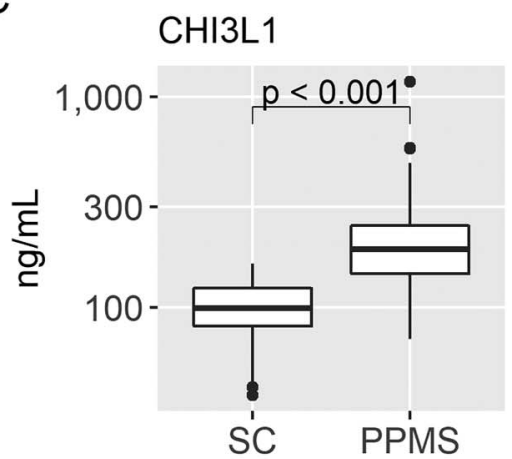

F<smiles></smiles>

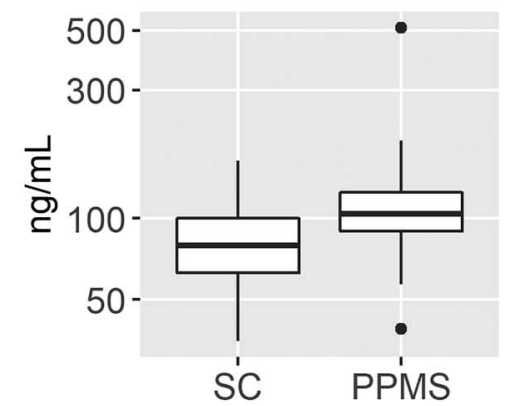

This figure shows concentrations of NFL, MBP, CHI3L1, sCD14, sCD27, and BCMA in CSF at screening in patients with PPMS ( $\mathrm{n}=59$ ) and symptomatic controls $(\mathrm{NFL}, \mathrm{CHI3L1}$, and BCMA $\mathrm{n}=35$; MBP $\mathrm{n}=31){ }^{18}$ The symptomatic controls were all included in the validation study of the immunoassays used for measuring CHI3L1, sCD14, sCD27, and BCMA. ${ }^{38}$ The patients with PPMS were older $(p<0.001)$ and more commonly male than the symptomatic controls $(p=0.001)$. $p$ values are based on ANCOVA with correction for age and sex. ANCOVA = analysis of covariance; sBCMA = soluble B-cell maturation antigen; MBP = myelin basic protein; NFL = neurofilament light chain; PPMS = primary progressive MS; sCD14 = soluble CD14; sCD27 = soluble CD27.

We investigated a panel of biomarkers of intrathecal inflammation which reflect activation of both the innate and adaptive intrathecal immune systems. ${ }^{22,23}$ However, we did not find anti-inflammatory effects induced by dimethyl fumarate in this study, despite the patients having elevated levels of most CSF biomarkers studied. We have previously shown that treatment with natalizumab and methylprednisolone reduces $\mathrm{sCD} 27$ concentrations in the CSF of patients with progressive MS and that $\mathrm{sCD} 27$ is associated with neuroaxonal damage assessed by the CSF concentration of NFL in progressive MS. ${ }^{24} \mathrm{CHI} 3 \mathrm{~L} 1$ has shown response to treatment with disease-modifying treatments in patients with RRMS. ${ }^{25-28}$ Thus, the inability of dimethyl fumarate to normalize the CSF levels of these 2 biomarkers suggests lack of efficacy of dimethyl fumarate. This conclusion is supported by the observation that dimethyl fumarate also had no effect on the inflammatory biomarkers BCMA and CD14. However, the latter might also reflect poor responsiveness because they have not previously been used for the assessment of response to treatment.

Compartmentalized intrathecal inflammation is highly manifested in patients with progressive MS and may not or only partially be targeted by systemically administered anti- inflammatory therapies. ${ }^{2,29}$ The lack of reduced intrathecal inflammation in this study may be related to this phenomenon.

The mean age and disease duration of the study population were higher than in other interventional trials involving patients with progressive MS. In addition, despite the evident intrathecal inflammation observed using CSF biomarkers, there was a low frequency of gadolinium-enhancing lesions in our study cohort compared with recent trials in progressive MS. ${ }^{1,30}$ The patients in this trial may have missed their window of opportunity for treatment with immunomodulatory or antioxidative drugs, or the treatment period may have been too short to prevent or reduce the neurodegenerative processes. $^{31}$ However, observational studies in patients with RRMS have indicated that dimethyl fumarate treatment reduces NFL levels in both serum and CSF after 1 year of treatment, and the same has been observed for other diseasemodifying therapies in patients with progressive MS. ${ }^{13,32}$

We found no between-group differences in any of the secondary MRI outcome measures. Spinal cord pathology is generally more pronounced in progressive MS compared with RRMS. ${ }^{33}$ This study evaluated spinal cord MRI cross-sectional area at the C2 level. A more dedicated spinal cord protocol might have added to 
Table 3 Adverse Events

\begin{tabular}{|c|c|c|}
\hline Adverse event & Placebo $(n=27)$ & Dimethyl fumarate $(n=27)$ \\
\hline Any adverse event, n (\%) & $16(59 \%)$ & $24(89 \%)$ \\
\hline \multicolumn{3}{|l|}{ Adverse event $\geq 5 \%$, n (\%) } \\
\hline Flushing & $1(4 \%)$ & $16(59 \%)$ \\
\hline Gastrointestinal pain & 0 & $6(22 \%)$ \\
\hline Nausea & $3(11 \%)$ & $3(11 \%)$ \\
\hline Diarrhea & $5(19 \%)$ & $4(15 \%)$ \\
\hline Vomiting & 0 & $2(7 \%)$ \\
\hline Upper respiratory infection & $4(15 \%)$ & $5(19 \%)$ \\
\hline Flu-like symptoms & $2(7 \%)$ & $5(19 \%)$ \\
\hline Fever & $1(4 \%)$ & $2(7 \%)$ \\
\hline Urinary tract infection & $2(7 \%)$ & $3(11 \%)$ \\
\hline Tooth infection & 0 & $2(7 \%)$ \\
\hline Back pain & $3(11 \%)$ & $2(7 \%)$ \\
\hline Fall & 0 & $2(7 \%)$ \\
\hline Fracture & $2(7 \%)$ & 0 \\
\hline Headache & 0 & $2(7 \%)$ \\
\hline Syncope & $2(7 \%)$ & 0 \\
\hline Eczema & $2(7 \%)$ & $1(4 \%)$ \\
\hline \multicolumn{3}{|l|}{ Lymphocyte count decrease; $n$ (\%) } \\
\hline Grade $2\left(<0.8-0.5 \times 10 \times 10 \mathrm{e}^{9} / \mathrm{L}\right)$ & $1(4 \%)$ & $8(30 \%)$ \\
\hline Grade $3\left(<0.5-0.2 \times 10 \times 10 \mathrm{e}^{9} / \mathrm{L}\right)$ & 0 & $5(19 \%)$ \\
\hline \multicolumn{3}{|l|}{ Adverse event by severity, $n$} \\
\hline Mild (grade 1) & 14 & 21 \\
\hline Moderate (grade 2) & 8 & 14 \\
\hline Severe (grade 3) & 3 & 6 \\
\hline Life-threatening (grade 4) & 0 & 2 \\
\hline Death (grade 5) & 0 & 0 \\
\hline Serious adverse events, $\mathbf{n}(\%)$ & $3(11 \%)$ & $3(11 \%)$ \\
\hline Gastroenteritis & $1(4 \%)^{a}$ & 0 \\
\hline Vertigo & $1(4 \%)^{a}$ & 0 \\
\hline Urinary tract infection & $1(4 \%)$ & 0 \\
\hline Testicular cancer, seminoma & 0 & $1(4 \%)^{b}$ \\
\hline Gallbladder pain & 0 & $1(4 \%)^{b}$ \\
\hline Sepsis, urosepsis & 0 & $1(4 \%)$ \\
\hline Treatment related serious adverse event & 0 & 0 \\
\hline Study withdrawal because of adverse event & 1 & 0 \\
\hline
\end{tabular}


the information on the CNS pathology of the patients. Because the study was not powered to detect significant differences in MRI outcomes, we limited the imaging studies to a comprehensive and fully validated MRI protocol of the brain.

The patients were relatively stable in their clinical assessments and cognitive abilities over the 48 weeks; some even improved. Several factors may cause these improvements. The study may be prone to recruitment and/or observation bias, the patients may experience recovery from subclinical relapses, or the improvements may reflect practice effects or inaccuracy in measuring. However, this study had very little interobserver bias because of very stable study personnel throughout the trial period. In addition, data were validated thoroughly by the study team and external monitors to assure data reliability.

Another limitation in this study is the high frequency of flushing and gastrointestinal pain in the treatment arm, which may have compromised blinding of investigators and patients. This was not investigated before unblinding but would not influence the results of the CSF biomarker analyses. In addition, the study investigated numerous secondary and tertiary endpoints without adjusting for multiple testing, and any significant findings should be interpreted with caution because of risk of type 2 errors.

We investigated the safety of dimethyl fumarate treatment in patients with PPMS. The safety profile of dimethyl fumarate is established in patients with RRMS in several clinical trials and because of its extensive clinical use. ${ }^{3,4,34}$ The number of adverse events was not similar between groups in our study. This can partly be explained by the known side effects of dimethyl fumarate, but we also found a higher prevalence of infections in the dimethyl fumarate group, especially influenza-like symptoms. This increase in infections may be due to higher susceptibility to infections in the dimethyl fumarate group in which we found a high proportion of patients with lymphopenia. However, the frequent occurrence of common adverse events in the dimethyl fumarate group, resulting in more frequent contact with trial personnel, may also have led to increased reporting of other adverse events, for example, infections. A similar pattern of an increased number of infections was seen in the dimethyl fumarate vs placebo or glatiramer acetate in patients with RRMS (CONFIRM) trial but in neither the phase 3 study of dimethyl fumarate for relapsing multiple sclerosis (DEFINE) nor the dimethyl fumarate monotherapy extension study in MS (ENDORSE). 3,4,34 The percentage of patients with lymphocyte counts below $0.5 \times 10^{9} / \mathrm{L}$ in this trial markedly exceeded the reported levels in the ENDORSE follow-up study (7\%-9\%). ${ }^{34}$ High age has previously been linked to the increased risk of dimethyl fumarate-induced lymphopenia; this may explain the high proportion of patients experiencing lymphopenia in this trial. ${ }^{35}$ In addition, the proportion of patients with flushing in this study was higher than reported in previous trials. In the placebo-controlled part of the study, there were 6 serious adverse events. The testicular seminoma in the dimethyl fumarate group was diagnosed after approximately 10 months of treatment with dimethyl fumarate, but whether there was a causal relationship with treatment is uncertain. Otherwise, cancer rates are similar between the dimethyl fumarate treated patients and the overall MS population. ${ }^{34,36}$ Safety will continue to be evaluated throughout the open-label phase of the study, and this will help determine the long-term safety profile of dimethyl fumarate treatment in patients with PPMS.

This trial uses changes in NFL in CSF as a primary outcome in a placebo-controlled trial. Analysis of serum concentrations of NFL by single-molecule array (SIMOA) analysis would have been beneficial for it being less invasive for the patients and increasingly used in clinical practice. However, few studies have shown that serum NFL analysis is superior to CSF NFL analysis. $^{37}$ Indeed, CSF levels of NFL are much higher than serum levels, and in this study, we found that the coefficient of variation for change in NFL over 48 weeks in the placebo group was $8.0 \%$ for CSF levels and $11.2 \%$ for serum levels measured by SIMOA (own unpublished observation). Despite the negative results regarding the primary outcome, we believe the trial is important and contributes to the development of NFL as a biomarker in future, controlled trials investigating new disease-modifying treatments for patients with MS. This may substantially reduce the costs of clinical trials and allow for fast track results. A priori, we estimated that the study would have $90 \%$ power to detect a $30 \%$ decrease in NFL in CSF. However, because there were fewer dropouts than expected and lower variability in the change in NFL in CSF in the placebo group than anticipated, we had $95 \%$ power to detect a $20 \%$ decrease and $80 \%$ power to detect a $16 \%$ decrease in NFL concentrations in the active arm of the study compared with the placebo arm, assuming that the $\mathrm{SD}$ of change would be comparable in both study arms.

This phase 2 trial of treatment with dimethyl fumarate in patients with PPMS showed no reduction in NFL levels in the CSF of patients treated with dimethyl fumarate compared with placebo. However, there was some reduction in the CSF concentration of $\mathrm{MBP}$ in the treatment group. This warrants further investigation of $\mathrm{MBP}$ as a treatment biomarker in PPMS.

\section{Acknowledgment}

The authors wish to pay special thanks to the study nurses Sidsel Walter Nielsen and Karina Jørgensen for their excellent assistance and meticulous work on the FUMAPMS study. The authors would like to thank the staff at our laboratory for producing high-quality assays and owe special thanks to Ulla Abildtrup, Lisbeth Egelykke Stolpe, and Birgit Højgaard Kassow for their thorough handling and analyses of samples. The authors would also like to thank MRI technician Sussi Larsen for her through work on planning and executing all MRI scans. The authors would also like to thank Sascha Gude and Hanne Schmidt for careful manual delineation of MS lesions on the structural MR scans and Nina Reislev for assisting in setting up the MR analyses.

\section{Study Funding}

This study was funded by a grant from Biogen (Cambridge, MA) and grants from the Danish Multiple Sclerosis Society 
(A33491, A35741, and A38444). Biogen also supplied study drug and placebo free of charge. Hartwig R. Siebner holds a 5 -year professorship in precision medicine at the Faculty of Health Sciences and Medicine, University of Copenhagen, which is sponsored by the Lundbeck Foundation (grant no. R186-2015-2138). Henrik Lundell has received funding from the European Research Council (ERC) under the European Union's Horizon 2020 research and innovation program (grant agreement no. 804746).

\section{Disclosure}

H.H. Chow reports nonfinancial support from Merck, nonfinancial support from Teva, nonfinancial support from Biogen, and nonfinancial support from Roche, outside the submitted work. J. Talbot reports nonfinancial support from Sanofi Genzyme, outside the submitted work. H. Lundell has a patent for performing diffusion-weighted magnetic resonance measurements on a sample pending to RWI $A B$. C. Gøbel Madsen has nothing to disclose. L. Marstrand reports grants from Novartis and personal fees from Biogen, outside the submitted work. T. Lange reports personal fees from Boehringer Ingelheim, personal fees from Leo Pharma, personal fees from BeiGene, and personal fees from Novo Nordisk, outside the submitted work. M. Reith Mahler reports nonfinancial support from Merck, outside the submitted work. S. Buhelt reports nonfinancial support from Merck and nonfinancial support from Biogen, outside the submitted work. R. Holm Hansen has nothing to disclose. M. Blinkenberg reports personal fees from Sanofi Genzyme, personal fees from Biogen, personal fees from Merck, personal fees from Novartis, personal fees from Teva, personal fees from Roche, nonfinancial support from Biogen, nonfinancial support from Roche, and nonfinancial support from Genzyme, outside the submitted work. J. Romme Christensen has nothing to disclose. P. Sorensen reports personal fees from Biogen, personal fees from Merck, personal fees from Novartis, personal fees from TEVA, personal fees from Celgene, and personal fees from Roche, outside the submitted work. M. Rode von Essen has nothing to disclose. H. Siebner reports personal fees from Sanofi Genzyme, personal fees from Springer Publishers, personal fees from Elsevier Publishers, personal fees from Lundbeck AS, personal fees from Gyldendal Publishers, and grants from Lundbeck Foundation, outside the submitted work. F. Sellebjerg reports grants from Biogen, grants from Danish Multiple Sclerosis Society during the conduct of the study, grants and personal fees from Biogen, personal fees from Lundbeck, grants and personal fees from Merck, grants and personal fees from Novartis, grants and personal fees from Roche, and grants and personal fees from Sanofi Genzyme, outside the submitted work. F. Sellebjerg is section editor on Multiple Sclerosis and Related Disorders. Go to Neurology. org/NN for full disclosures.

\section{Publication History}

Received by Neurology: Neuroimmunology \& Neuroinflammation January 5, 2021. Accepted in final form May 17, 2021.

\section{Appendix Authors}

\begin{tabular}{|c|c|c|}
\hline Name & Location & Contribution \\
\hline $\begin{array}{l}\text { Helene } \\
\text { Højsgaard } \\
\text { Chow, PhD }\end{array}$ & $\begin{array}{l}\text { Danish Multiple Sclerosis } \\
\text { Center, Copenhagen } \\
\text { University Hospital } \\
\text { Rigshospitalet Glostrup, } \\
\text { Denmark }\end{array}$ & $\begin{array}{l}\text { Contributed to the study } \\
\text { concept and design; } \\
\text { designed and wrote the study } \\
\text { protocol; were principal } \\
\text { investigator; contributed to } \\
\text { data collection, data analysis, } \\
\text { data interpretation; drafted } \\
\text { first version of the article; and } \\
\text { created tables and figures }\end{array}$ \\
\hline
\end{tabular}

\begin{tabular}{lll}
\hline Jacob Talbot, & $\begin{array}{l}\text { Danish Multiple Sclerosis } \\
\text { MD }\end{array}$ & $\begin{array}{l}\text { Designed and wrote the } \\
\text { Center, Copenhagen }\end{array}$ \\
University Hospital & principal investigator; \\
Rigshospitalet Glostrup, & contributed to data \\
Denmark & collection, data analysis, \\
& data interpretation; drafted \\
& first version of the article; \\
& created tables and figures; \\
& and contributed to \\
& laboratory analyses
\end{tabular}

\begin{tabular}{|c|c|c|}
\hline $\begin{array}{l}\text { Henrik } \\
\text { Lundell, PhD }\end{array}$ & $\begin{array}{l}\text { Danish Research Centre for } \\
\text { Magnetic Resonance, Centre } \\
\text { for Functional and } \\
\text { Diagnostic Imaging and } \\
\text { Research, Copenhagen } \\
\text { University Hospital } \\
\text { Hvidovre, Denmark }\end{array}$ & $\begin{array}{l}\text { Contributed to data } \\
\text { collection, study design and } \\
\text { the analysis of MRI data, and } \\
\text { revised the article for } \\
\text { intellectual content }\end{array}$ \\
\hline $\begin{array}{l}\text { Camilla } \\
\text { Gøbel } \\
\text { Madsen, MD }\end{array}$ & $\begin{array}{l}\text { Danish Research Centre for } \\
\text { Magnetic Resonance, Centre } \\
\text { for Functional and } \\
\text { Diagnostic Imaging and } \\
\text { Research, Copenhagen } \\
\text { University Hospital } \\
\text { Hvidovre, Denmark }\end{array}$ & $\begin{array}{l}\text { Contributed to data } \\
\text { collection, study design and } \\
\text { the analysis of MRI data; } \\
\text { performed safety evaluation } \\
\text { of MRI; and revised the } \\
\text { article for intellectual } \\
\text { content }\end{array}$ \\
\hline
\end{tabular}

Lisbet Danish Multiple Sclerosis Performed evaluation of the

Marstrand, Center, Copenhagen brief visuospatial memory

PhD University Hospital test-revised and revised the Rigshospitalet Glostrup, article for intellectual Denmark content

\begin{tabular}{|c|c|c|}
\hline $\begin{array}{l}\text { Theis Lange, } \\
\text { PhD }\end{array}$ & $\begin{array}{l}\text { Department of Public } \\
\text { Health, Section of } \\
\text { Biostatistics, Copenhagen } \\
\text { University, Denmark }\end{array}$ & $\begin{array}{l}\text { Contributed to the design of } \\
\text { the statistical methods and } \\
\text { revised the article for } \\
\text { intellectual content }\end{array}$ \\
\hline $\begin{array}{l}\text { Mie Mahler, } \\
\text { MD }\end{array}$ & $\begin{array}{l}\text { Danish Multiple Sclerosis } \\
\text { Center, Copenhagen } \\
\text { University Hospital } \\
\text { Rigshospitalet Glostrup, } \\
\text { Denmark }\end{array}$ & $\begin{array}{l}\text { Contributed to laboratory } \\
\text { analyses and revised the } \\
\text { article for intellectual } \\
\text { content }\end{array}$ \\
\hline $\begin{array}{l}\text { Sophie } \\
\text { Buhelt, PhD }\end{array}$ & $\begin{array}{l}\text { Danish Multiple Sclerosis } \\
\text { Center, Copenhagen University } \\
\text { Hospital Rigshospitalet } \\
\text { Glostrup, Denmark }\end{array}$ & $\begin{array}{l}\text { Contributed to data } \\
\text { collection and revised the } \\
\text { article for intellectual } \\
\text { content }\end{array}$ \\
\hline $\begin{array}{l}\text { Rikke Holm } \\
\text { Hansen, MSc }\end{array}$ & $\begin{array}{l}\text { Danish Multiple Sclerosis } \\
\text { Center, Copenhagen } \\
\text { University Hospital } \\
\text { Rigshospitalet Glostrup, } \\
\text { Denmark }\end{array}$ & $\begin{array}{l}\text { Contributed to laboratory } \\
\text { analyses and revised the } \\
\text { article for intellectual } \\
\text { content }\end{array}$ \\
\hline $\begin{array}{l}\text { Morten } \\
\text { Blinkenberg, } \\
\text { PhD }\end{array}$ & $\begin{array}{l}\text { Danish Multiple Sclerosis } \\
\text { Center, Copenhagen } \\
\text { University Hospital } \\
\text { Rigshospitalet Glostrup, } \\
\text { Denmark }\end{array}$ & $\begin{array}{l}\text { Contributed to data } \\
\text { collection and revised the } \\
\text { article for intellectual } \\
\text { content }\end{array}$ \\
\hline $\begin{array}{l}\text { Jeppe } \\
\text { Romme } \\
\text { Christensen, } \\
\text { PhD }\end{array}$ & $\begin{array}{l}\text { Danish Multiple Sclerosis } \\
\text { Center, Copenhagen } \\
\text { University Hospital } \\
\text { Rigshospitalet Glostrup, } \\
\text { Denmark }\end{array}$ & $\begin{array}{l}\text { Conceptualized the study; } \\
\text { contributed to data } \\
\text { collection; and revised the } \\
\text { article for intellectual } \\
\text { content }\end{array}$ \\
\hline
\end{tabular}


Appendix (continued)

\begin{tabular}{|c|c|c|}
\hline Name & Location & Contribution \\
\hline $\begin{array}{l}\text { Per Soelberg } \\
\text { Sørensen, } \\
\text { DMSc }\end{array}$ & $\begin{array}{l}\text { Danish Multiple Sclerosis } \\
\text { Center, Copenhagen } \\
\text { University Hospital } \\
\text { Rigshospitalet Glostrup, } \\
\text { Denmark }\end{array}$ & $\begin{array}{l}\text { Conceptualized the study } \\
\text { and revised the article for } \\
\text { intellectual content }\end{array}$ \\
\hline $\begin{array}{l}\text { Marina von } \\
\text { Essen, PhD }\end{array}$ & $\begin{array}{l}\text { Danish Multiple Sclerosis } \\
\text { Center, Copenhagen } \\
\text { University Hospital } \\
\text { Rigshospitalet Glostrup, } \\
\text { Denmark }\end{array}$ & $\begin{array}{l}\text { Contributed to laboratory } \\
\text { analyses and revised the } \\
\text { article for intellectual } \\
\text { content }\end{array}$ \\
\hline $\begin{array}{l}\text { Hartwig } \\
\text { Roman } \\
\text { Siebner, } \\
\text { DMSc }\end{array}$ & $\begin{array}{l}\text { Danish Research Centre for } \\
\text { Magnetic Resonance, Centre } \\
\text { for Functional and } \\
\text { Diagnostic Imaging and } \\
\text { Research, Copenhagen } \\
\text { University Hospital } \\
\text { Hvidovre, Denmark }\end{array}$ & $\begin{array}{l}\text { Contributed to data } \\
\text { collection, study design and } \\
\text { the analysis of MRI data, and } \\
\text { revised the article for } \\
\text { intellectual content }\end{array}$ \\
\hline $\begin{array}{l}\text { Finn } \\
\text { Sellebjerg, } \\
\text { DMSc }\end{array}$ & $\begin{array}{l}\text { Danish Multiple Sclerosis } \\
\text { Center, Copenhagen } \\
\text { University Hospital } \\
\text { Rigshospitalet Glostrup, } \\
\text { Denmark }\end{array}$ & $\begin{array}{l}\text { Conceptualized the study; } \\
\text { designed and wrote the } \\
\text { study protocol; and revised } \\
\text { the article for intellectual } \\
\text { content }\end{array}$ \\
\hline
\end{tabular}

\section{References}

1. Montalban X, Hauser SL, Kappos L, et al. Ocrelizumab versus placebo in primary progressive multiple sclerosis. N Engl J Med. 2017;376(3):209-220.

2. Gajofatto A, Turatti M, Benedetti MD. Primary progressive multiple sclerosis: current therapeutic strategies and future perspectives. Expert Rev Neurotherapeutics. 2017; 17(4):393-406.

3. Fox RJ, Miller DH, Phillips JT, et al. Placebo-controlled phase 3 study of oral BG-12 or glatiramer in multiple sclerosis. N Engl J Med. 2012;367(12):1087-1097.

4. Gold R, Kappos L, Olsson TP, et al. Placebo-controlled phase 3 study of oral BG-12 for relapsing multiple sclerosis. N Engl J Med. 2012;367(12):1098-1107.

5. Strassburger Krogias K, Ellrichmann G, Krogias C, Altmeyer P, Chan A, Gold R. Fumarate treatment in progressive forms of multiple sclerosis: first results of a singlecenter observational study. Ther Adv Neurol Disord. 2014;7(5):232-238.

6. Montes Diaz G, Hupperts R, Fraussen J, Somers V. Dimethyl fumarate treatment in multiple sclerosis: recent advances in clinical and immunological studies. Autoimmun Rev. 2018;17:1240-1250.

7. Holm Hansen R, Højsgaard Chow H, Sellebjerg F, Rode von Essen M. Dimethyl fumarate therapy suppresses $\mathrm{B}$ cell responses and follicular helper $\mathrm{T}$ cells in relapsingremitting multiple sclerosis. Mult Scler J. 2019;25(9):1289-1297.

8. Killestein J, Reder AT. Dimethyl fumarate-induced changes in the MS lymphocyte repertoire: No need for subset monitoring. Neurology. 2019;92(15):696-697.

9. Chataway J, De Angelis F, Connick P, et al. Efficacy of three neuroprotective drugs in secondary progressive multiple sclerosis (MS-SMART): a phase $2 \mathrm{~b}$, multiarm, double-blind, randomised placebo-controlled trial. Lancet Neurol. 2020;19(3): 214-225.

10. Fox RJ, Coffey CS, Conwit R, et al. Phase 2 trial of ibudilast in progressive multiple sclerosis. N Engl J Med. 2018;379(9):846-855.

11. Ratzer R, Iversen P, Bornsen L, et al. Monthly oral methylprednisolone pulse treatment in progressive multiple sclerosis. Mult Scler. 2016;22(7):926-934.

12. Christensen JR, Ratzer R, Börnsen L, et al. Natalizumab in progressive MS: results of an open-label, phase 2A, proof-of-concept trial. Neurology. 2014;82(17):1499-1507.

13. Kapoor R, Smith KE, Allegretta M, et al. Serum neurofilament light as a biomarker in progressive multiple sclerosis. Neurology. 2020;95(10):436-444.
14. Kuhle J, Kropshofer H, Haering DA, et al. Blood neurofilament light chain as biomarker of MS disease activity and treatment response. Neurology. 2019;92(10): E1007-E1015.

15. Sormani MP, Haering DA, Kropshofer H, et al. Blood neurofilament light as a potential endpoint in Phase 2 studies in MS. Ann Clin Transl Neurol. 2019;6(6):1081-9.

16. Kuhle J, Barro C, Andreasson U, et al. Comparison of three analytical platforms for quantification of the neurofilament light chain in blood samples: ELISA, electrochemiluminescence immunoassay and Simoa. Clin Chem Lab Med. 2016;54(10) 1655-1661.

17. Kuhle J, Plattner K, Bestwick JP, et al. A comparative study of CSF neurofilament light and heavy chain protein in MS. Mult Scler J. 2013;19(12):1597-1603.

18. Teunissen $\mathrm{C}$, Menge $\mathrm{T}$, Altintas A, et al. Consensus definitions and application guidelines for control groups in cerebrospinal fluid biomarker studies in multiple sclerosis. Mult Scler J. 2013;19(13):1802-1809.

19. Romme Christensen J, Börnsen L, Khademi M, et al. CSF inflammation and axonal damage are increased and correlate in progressive multiple sclerosis. Mult Scler J. 2013, 19(7):877-884.

20. Sellebjerg F, Christiansen M, Jensen J, Frederiksen JL. Immunological effects of oral high-dose methylprednisolone in acute optic neuritis and multiple sclerosis. Eur J Neurol. 2000;7(3):281-289.

21. Lamers KJB, Uitdehaag BMJ, Hommes OR, Doesburg W, Wevers RA, Geel WJ. The short-term effect of an immunosuppressive treatment on CSF myelin basic protein in chronic progressive multiple sclerosis. J Neurol Neurosurg Psychiatry. 1988;51(10): 1334-1337.

22. Barbour C, Kosa P, Komori M, et al. Molecular-based diagnosis of multiple sclerosis and its progressive stage. Ann Neurol. 2017;82(5):795-812.

23. Komori M, Blake A, Greenwood M, et al. Cerebrospinal fluid markers reveal in trathecal inflammation in progressive multiple sclerosis. Ann Neurol. 2015;78(1):3-20.

24. Romme Christensen J, Komori M, von Essen MR, et al. CSF inflammatory biomarkers responsive to treatment in progressive multiple sclerosis capture residual inflammation associated with axonal damage. Mult Scler J. 2019;25(7):937-946.

25. Novakova L, Axelsson M, Khademi M, et al. Cerebrospinal fluid biomarkers of inflammation and degeneration as measures of fingolimod efficacy in multiple sclerosis. Mult Scler. 2017;23(1):62-71

26. Novakova L, Zetterberg $\mathrm{H}$, Sundström $\mathrm{P}$, et al. Monitoring disease activity in multiple sclerosis using serum neurofilament light protein. Neurology. 2017;89(22):2230-2237.

27. Malmeström C, Axelsson M, Lycke J, Zetterberg H, Blennow K, Olsson B. CSF levels of YKL-40 are increased in MS and replaces with immunosuppressive treatment. J Neuroimmunol. 2014;269(1-2):87-89.

28. Matute-Blanch C, Río J, Villar LM, et al. Chitinase 3-like 1 is associated with the response to interferon-beta treatment in multiple sclerosis. J Neuroimmunol. 2017;303:62-65.

29. Lassmann H. Pathogenic mechanisms associated with different clinical courses of multiple sclerosis. Front Immunol. 2019;9:3116.

30. Lublin F, Miller DH, Freedman MS, et al. Oral fingolimod in primary progressive multiple sclerosis (INFORMS): a phase 3, randomised, double-blind, placebocontrolled trial. Lancet. 2016;387(10023):1075-1084.

31. Sorensen PS, Fox RJ, Comi G. The window of opportunity for treatment of progressive multiple sclerosis. Curr Opin Neurol. 2020;33(3):262-270.

32. Sejbaek T, Nielsen HH, Penner N, et al. Dimethyl fumarate decreases neurofilament light chain in CSF and blood of treatment naïve relapsing MS patients. J Neurol Neurosurg Psychiatry. 2019;90(12):1324-1330.

33. Garriga JS-, Pareto D, Battaglini M, et al. MAGNIMS consensus recommendations on the use of brain and spinal cord atrophy measures in clinical practice. Nat Rev Neurol. 2020;16(3):171-182

34. Gold R, Arnold DL, Bar-Or A, et al. Long-term effects of delayed-release dimethyl fumarate in multiple sclerosis: interim analysis of ENDORSE, a randomized extension study. Mult Scler. 2017;23(2):253-265.

35. Morales FS, Koralnik IJ, Gautam S, Samaan S, Sloane JA. Risk factors for lymphopenia in patients with relapsing-remitting multiple sclerosis treated with dimethyl fumarate. J Neurol. 2020;267(1):125-131.

36. Lebrun C, Rocher F. Cancer risk in patients with multiple sclerosis: potential impact of disease-modifying drugs. In CNS Drugs, Vol. 32. Springer International Publishing; 2018:939-949.

37. de Flon P, Laurell K, Sundström P, et al. Comparison of plasma and cerebrospinal fluid neurofilament light in a multiple sclerosis trial. Acta Neurol Scand. 2019;139(5): 462-468.

38. Mahler MR, Søndergaard HB, Buhelt S, et al. Multiplex assessment of cerebrospinal fluid biomarkers in multiple sclerosis. Mult Scler Relat Disord. 2020;45:102391. 


\title{
Neurology \\ Neuroimmunology \& Neuroinflammation
}

\author{
Dimethyl Fumarate Treatment in Patients With Primary Progressive Multiple \\ Sclerosis: A Randomized, Controlled Trial \\ Helene Højsgaard Chow, Jacob Talbot, Henrik Lundell, et al. \\ Neurol Neuroimmunol Neuroinflamm 2021;8; \\ DOI 10.1212/NXI.0000000000001037
}

This information is current as of August 24, 2021

\section{Updated Information \& Services}

References

Subspecialty Collections

Permissions \& Licensing

Reprints including high resolution figures, can be found at:

http://nn.neurology.org/content/8/5/e1037.full.html

This article cites 38 articles, 2 of which you can access for free at: http://nn.neurology.org/content/8/5/e1037.full.html\#\#ref-list-1

This article, along with others on similar topics, appears in the following collection(s):

Clinical trials Randomized controlled (CONSORT agreement)

http://nn.neurology.org//cgi/collection/clinical_trials_randomized_cont rolled_consort_agreement

Multiple sclerosis

http://nn.neurology.org//cgi/collection/multiple_sclerosis

Information about reproducing this article in parts (figures,tables) or in its entirety can be found online at:

http://nn.neurology.org/misc/about.xhtml\#permissions

Information about ordering reprints can be found online:

http://nn.neurology.org/misc/addir.xhtml\#reprintsus

Neurol Neuroimmunol Neuroinflamm is an official journal of the American Academy of Neurology.

Published since April 2014, it is an open-access, online-only, continuous publication journal. Copyright

Copyright (C) 2021 The Author(s). Published by Wolters Kluwer Health, Inc. on behalf of the American

Academy of Neurology.. All rights reserved. Online ISSN: 2332-7812.

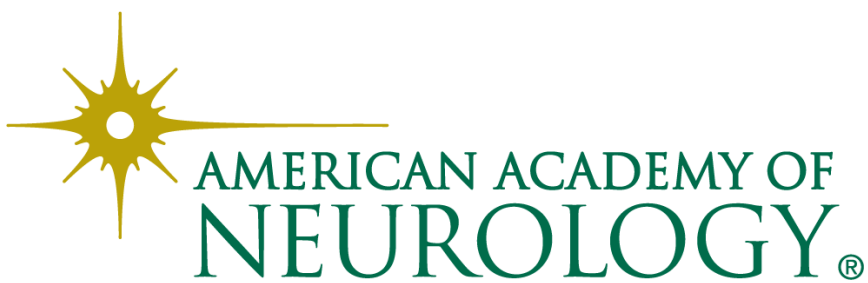

